\title{
Avaliação econômica de dietas com diferentes níveis de substituição do grão de sorgo por grão de aveia preta para terminação de novilhos em confinamento ${ }^{1}$
}

\author{
Economic evaluation of diets with different levels of substitution of sorghum grain by oat grain for \\ steers during the feedlot finishing
}

\author{
Cristian Faturi ${ }^{2}$ João Restle ${ }^{3} \quad$ Leonir Luiz Pascoal $^{4}$ Liliane Cerdótes $^{5}$ \\ Rômulo Augusto Guedes Rizzardo ${ }^{6}$ Aline Kellermann de Freitas ${ }^{6}$
}

\section{RESUMO}

\begin{abstract}
Foi estudada a economicidade da utilização de quatro niveis de substituição $(0 ; 33 ; 66$ e 100\%) do grão de sorgo (Sorghum bicolor L. Moench) por grão de aveia preta (Avena strigosa) na fração concentrado da dieta de novilhos, na fase de terminação em confinamento. Os animais, com idade média inicial de 19 meses e peso médio inicial de $381 \mathrm{~kg}$, foram alimentados com dieta composta por $60 \%$ de volumoso e $40 \%$ de concentrado, contendo proteina bruta para ganho de peso de $1,2 \mathrm{~kg}$ animal ${ }^{-1}$ dia $^{-1}$. No período de adaptação de sete dias e na primeira metade do período experimental (35 dias), o volumoso utilizado foi a silagem de sorgo forrageiro, na segunda metade do periodo experimental (32 dias), o volumoso utilizado foi a silagem de milho (Zea mays). Quando foi utilizada a silagem de sorgo, os custos das dietas por animal por dia foram de $R S$ 1,$062 ; 0,970 ; 0,865$ e 0,725, respectivamente, para os niveis de substituição de 0; 33; 66 e 100\%. Já os custos das dietas para produção de $1 \mathrm{~kg}$ de ganho de peso foram de $R \$ 0,82$; 0,$74 ; 0,78$ e 0,65, respectivamente. Quando foi utilizada a silagem de milho, os custos das dietas aumentaram em função do aumento no consumo de matéria seca e do maior custo de produção da silagem de milho. No entanto, foi mantido o ganho de peso médio diário próximo ao preconizado $(1,2 \mathrm{~kg}$ animal $\left.{ }^{-1}\right)$. Os custos das dietas por animal por dia que continham silagem de milho foram de $R \$ 1,401 ; 1,208 ; 1,063$ e 0,906 e R\$ 1,083; 1,011; 0,799 e 0,916 para produção de $1 \mathrm{~kg}$ de ganho de peso, respectivamente, para os niveis de substituição de 0; 33; 66 e 100\%. Os custos totais das diferentes dietas por animal no periodo de 67 dias foram de $R \$ 82,517 ; 72,959 ; 64,587$ e 54,645, sendo obtida uma
\end{abstract}

receita bruta por animal de $R \$ 95,22 ; 92,20 ; 89,66$ e 77,46, originando uma diferença positiva de $R \$ 12,70 ; 19,24 ; 25,07$ e 22,81 por animal, respectivamente, para os niveis de substituição de 0; 33; 66 e 100\%.

Palavras-chave: custos em confinamento, custo do ganho de peso, dietas alternativas, economicidade em bovinocultura, receitas.

\section{ABSTRACT}

The economic evaluation of the use of four substitution levels $(0 ; 33 ; 66$ e 100\%) of sorghum grain (Sorghum bicolor L. Moench) by oat grain (Avena strigosa) in the concentrate of diet of steers during feedlot finishing, was studied. The animals, 19 months old and with initial average weight of $381 \mathrm{~kg}$, were fed a diet with $60 \%$ of roughage and $40 \%$ of concentrate, containing crude protein for a weight gain of $1.2 \mathrm{~kg} /$ animal/day. During the adaptation period and the first half of the experimental period (35 days) the roughage used was sorghum silage, during the second half of the experimental period (32 days) the roughage used was corn silage (Zea mays). When sorghum silage was used the costs of the diet per animal per day were $R \$ 1.062 ; 0.970$; 0.865 and 0.725 , respectively, for the substitution levels 0 ; 33; 66 and 100\%. The diet costs to produce $1 \mathrm{~kg}$ of weight gain were $R \$ 0.82 ; 0.74 ; 0.78$ and 0.65 , respectively. When corn silage was used, the cost of the diets increased as a result of the increase in dry matter intake and the higher production cost of corn silage, however, the daily weight gain was maintained close to $1.2 \mathrm{~kg}$ animal $^{-1}$ as preconized. The costs per animal per day of diets containing corn silage were

${ }^{1}$ Parte da Dissertação de Mestrado do primeiro autor.

${ }^{2}$ Zootecnista, Aluno do Curso de Pós-graduação em Zootecnia da Universidade Federal de Santa Maria (UFSM). Email: cfaturi@bol.com.br ${ }^{3}$ Engenheiro Agrônomo, PhD, Professor Titular, Departamento de Zootecnia, UFSM, Camobi, 97105-900, Santa Maria-RS. Email: jorestle@ccr.ufsm.br. Autor para correspondência.

${ }^{4} \mathrm{MSc}$, Professor Assistente, Departamento de Zootecnia, UFSM.

${ }^{5}$ Zootecnista, Aluna do Curso de Pós-graduação em Zootecnia, UFSM.

${ }^{6}$ Aluno do Curso de Graduação em Zootecnia, UFSM, bolsista IC-FAPERGS. 
$R \$ 1.401 ; 1.208 ; 1.063$ and 0.906 and $R \$ 1.083 ; 1.011 ; 0.799$ and 0.916 for the production of $1 \mathrm{~kg}$ of weight gain, respectively, for the substitution levels 0; 33; 66 and 100\%. Total costs of the different diets per animal during the whole period of 67 days were $R \$ 82.517 ; 72.959 ; 64.587$ and 54.645 , resulting a gross income per animal of $R \$ 95.22$; $92.20 ; 89.66$ and 77.46 , originating a positive difference of $R \$ 12.70$; 19.24; 25.07 and 22.81 per animal, respectively, for substitution levels $0 ; 33 ; 66$ and $100 \%$.

Key words: costs in feedlot, cost of weight gain, alternative diets, economics in beef cattle, income

\section{INTRODUÇÃO}

Há poucos anos, a atividade de confinamento de bovinos no Brasil tinha como principal justificativa o aproveitamento do diferencial de preços do boi gordo, entre a safra e a entressafra. Além de abater um bovino mais novo, com acabamento adequado, ou de aproveitar subprodutos na sua alimentação, a motivação dos confinadores era o abate dos bovinos na entressafra e o recebimento de um valor da arroba, pelo menos $30 \%$ mais alto do que o praticado na safra (BÜRGI, 2001).

Entretanto, este diferencial de entressafra vem sendo reduzido (ANUALPEC, 2000), com práticas de melhoramento forrageiro, técnicas de suplementação, pastagens cultivadas e confinamento. Como conseqüência, técnicos e produtores foram obrigados a produzir com mais eficiência econômica no confinamento.

Para RESTLE \& VAZ (1999), a alimentação é responsável por aproximadamente $70 \%$ do custo total do confinamento, sendo que, ao redor de $80 \%$, são relativos ao custo do alimento concentrado utilizado na dieta. Concentrados mais energéticos são indicados para a alimentação de bovinos, embora possam ter custos limitantes ocasionados por fatores de produção, preços internacionais e pela oferta. Um exemplo foi a grande oferta do grão de aveia preta no ano 2000 (VAZ et al. 2000), devido ao excedente proveniente principalmente das regiões das Missões e Planalto Médio, determinando uma redução no preço da aveia

Segundo RESTLE et al. (2000) a apreciação econômica dos custos com alimentação dentro do sistema de confinamento torna-se importante, pois nem sempre a melhor resposta biológica representa a melhor resposta econômica. $\mathrm{Na}$ avaliação do confinamento, outros benefícios indiretos ao sistema de ciclo completo devem ser considerados, como a aceleração do giro de capital, redução da carga animal das pastagens durante o inverno, programação da data de comercialização dos animais e abate de animais mais jovens de melhor qualidade de carcaça e carne (PASCOAL et al., 1999).

O objetivo deste trabalho foi avaliar a economicidade da alimentação com silagens de sorgo ou de milho, adicionadas de concentrado com níveis crescentes de substituição do grão de sorgo por grão de aveia, para terminação de novilhos em confinamento.

\section{MATERIAL E MÉTODOS}

O experimento foi conduzido no Setor de Bovinocultura de Corte do Departamento de Zootecnia da Universidade Federal de Santa Maria, localizado no município de Santa Maria-RS. Foram confinados, para terminação, 48 novilhos Charolês, Nelore e seus mestiços, tomados ao acaso do rebanho experimental do Departamento de Zootecnia, criados e recriados sob as mesmas condições de manejo e alimentação, com peso médio inicial de $381 \mathrm{~kg}$ e idade média inicial de 19 meses. Os animais foram divididos em 12 lotes, equilibrados por grupo genético, peso e estado corporal, entre os quais foram sorteados os tratamentos, que eram constituídos por quatro níveis de substituição do grão de sorgo por grão de aveia preta no concentrado, sendo assim identificados: T0 = concentrado com $100 \%$ de sorgo; T33 = concentrado com $66 \%$ de sorgo e $33 \%$ de aveia preta; T66 = concentrado com $33 \%$ de sorgo e $66 \%$ de aveia preta; $\mathrm{T} 100=$ concentrado com $100 \%$ de aveia preta.

O período experimental foi subdivido em dois subperíodos. No primeiro, de 35 dias, os animais foram alimentados com silagem de sorgo forrageiro AG2002 como fonte de volumoso; no segundo, de 32 dias, o volumoso foi a silagem de milho AG122. A utilização da silagem de sorgo forrageiro na primeira metade do período de confinamento deve-se ao seu menor custo de produção. A utilização da silagem de milho para a segunda metade do período foi em função da sua maior concentração energética, visando manter o mesmo ritmo de ganho de peso, já que os animais necessitam maior aporte energético devido à composição do ganho que vai se alterando com um maior grau de acabamento (NRC, 1996).

Durante o confinamento, os animais foram alimentados ad libitum, com uma dieta calculada (NRC, 1984) para fornecer proteína bruta suficiente para ganho de peso de $1,2 \mathrm{~kg}$ por animal por dia. As composições dos concentrados estão apresentadas na tabela 1 .

Os animais foram alojados em doze baias pavimentadas de $20 \mathrm{~m}^{2}$, em confinamento semicoberto, 
Tabela 1 - Composição dos concentrados (\%) utilizados na alimentação dos novilhos, de acordo com o nível de substituição e o tipo de silagem

\begin{tabular}{|c|c|c|c|c|c|c|c|c|}
\hline \multirow{3}{*}{ Ingredientes } & \multicolumn{8}{|c|}{ Nível de substituição/silagem* } \\
\hline & \multicolumn{2}{|c|}{$0 \%$ de aveia } & \multicolumn{2}{|c|}{$33 \%$ de aveia } & \multicolumn{2}{|c|}{$66 \%$ de aveia } & \multicolumn{2}{|c|}{$100 \%$ de aveia } \\
\hline & $\begin{array}{c}\text { Silagem } \\
\text { Sorgo }\end{array}$ & $\begin{array}{l}\text { Silagem } \\
\text { Milho }\end{array}$ & $\begin{array}{c}\text { Silagem } \\
\text { Sorgo }\end{array}$ & $\begin{array}{l}\text { Silagem } \\
\text { Milho }\end{array}$ & $\begin{array}{c}\text { Silagem } \\
\text { Sorgo }\end{array}$ & $\begin{array}{c}\text { Silagem } \\
\text { Milho }\end{array}$ & $\begin{array}{c}\text { Silagem } \\
\text { Sorgo }\end{array}$ & $\begin{array}{c}\text { Silagem } \\
\text { Milho }\end{array}$ \\
\hline Grão de sorgo & 95,36 & 96,27 & 64,14 & 64,75 & 32,36 & 32,66 & - & - \\
\hline Grão de Aaveia & - & - & 32,07 & 32,38 & 64,69 & 65,31 & 97,90 & 98,83 \\
\hline Uréia & 3,12 & 2,49 & 2,30 & 1,66 & 1,48 & 0,84 & 0,66 & - \\
\hline Calcário calcítico & 1,02 & 0,74 & 0,99 & 0,71 & 0,97 & 0,69 & 0,95 & 0,67 \\
\hline Sal & 0,50 & 0,50 & 0,50 & 0,50 & 0,50 & 0,50 & 0,50 & 0,50 \\
\hline
\end{tabular}

* Todos os concentrados continham 62 ppm de monensina sódica

providas de comedouro e bebedouro. Os animais foram confinados no dia 21 de maio, submetidos à adaptação por uma semana, sendo pesados no início e final do período de adaptação, bem como ao final de cada subperíodo de alimentação.

Para avaliação dos custos e receitas, foram utilizados os valores, em reais, correspondentes a cada componente da dieta e ao preço do boi gordo no período em que foi realizado o experimento. O custo das dietas foi calculado considerando-se o consumo de matéria seca de silagem e de concentrado, não tendo sido considerados desperdícios no ato da alimentação e sobras no cocho. Para compor os custo dos concentrados, considerou-se apenas o preço de aquisição no mercado, sem levar em conta a elaboração dos concentrados. Não foram considerados o custo da mão-de-obra para alimentar os animais, a depreciação das instalações e custo financeiro dos recursos utilizados.

A variabilidade na aptidão das microrregiões para produzir silagem faz com que se obtenha também variabilidade no custo de sua produção. Para o cálculo do custo da silagem, foram considerados aqueles citados por NEUMAN (2001). A margem da operação foi obtida através da diferença entre a receita bruta e o custo da dieta.

\section{RESULTADOS E DISCUSSÃO}

A apreciação econômica refere-se aos alimentos utilizados, já que estes representam o principal componente na terminação de bovinos confinados, ou seja, cerca de 70\% (RESTLE \& VAZ, 1999). Os demais componentes não serão considerados tendo em vista a dificuldade da sua estimativa em instituições de pesquisa. A discussão é feita em função do nível de aveia preta em substituição ao grão de sorgo na fração concentrado da dieta e do tipo de silagem. Este último está fundido com o subperíodo de alimentação, em função das diferenças na composição do concentrado utilizado com cada silagem e no custo das duas silagens. Na tabela 2, são apresentados os dados médios de desempenho e custo com alimentação dos novilhos durante a primeira fase do confinamento, utilizando-se a silagem de sorgo forrageiro. Observa-se que o consumo de matéria seca foi semelhante entre os diferentes tratamentos fazendo com que o custo com alimentação por animal variasse, principalmente em função da diferença no preço do grão de sorgo $\left(0,18 \mathrm{R} \$ \mathrm{~kg}^{-1}\right)$ em relação ao grão de aveia $(0,11 \mathrm{R} \$ / \mathrm{kg})$. Em função deste fator, o custo do concentrado com $100 \%$ de grão de sorgo, para cada animal por dia, foi de $0,814 \mathrm{R} \$ \mathrm{dia}^{-1}, 68,88 \%$ maior que o custo do concentrado com base no grão de aveia preta $\left(0,482 \mathrm{R} \$ \operatorname{dia}^{-1}\right)$. A diferença no custo com concentrado refletiu-se diretamente no custo com alimentação, ocorrendo uma queda à medida que aumentou o nível de aveia no concentrado.

No presente experimento, o custo com concentrado representou 76,65; 74,12; 70,75 e 66,48\% do custo total da alimentação, o que ressalta a importância da escolha adequada dos componentes da ração. VAZ et al. (2000), em um estudo sobre alimentos e níveis de concentrado para confinamento de bovinos de corte, encontraram uma gama de alimentos com diferentes custos, e diferentes desempenhos animal, o que demonstra a importância do ajuste do concentrado em função do retorno econômico.

Na tabela 2, observa-se ainda, que o custo com alimentação para produzir um quilograma de ganho de peso foi superior para os tratamentos com maior proporção de sorgo no concentrado. No entanto, a diferença percentual foi menor em relação à diferença

Ciência Rural, v. 33, n. 5, set-out, 2003. 
Tabela 3 - Apreciação econômica do sistema produtivo durante a segunda fase do confinamento com silagem de milho

\begin{tabular}{|c|c|c|c|c|}
\hline \multirow{2}{*}{ Itens } & \multicolumn{4}{|c|}{ Nível de substituição } \\
\hline & $0 \%$ aveia & $33 \%$ aveia & $66 \%$ aveia & $100 \%$ aveia \\
\hline Consumo de MS, kg/animal/dia & 11,233 & 10,690 & 10,521 & 10,201 \\
\hline Ganho de peso, kg/animal/dia & 1,294 & 1,195 & 1,331 & 0,990 \\
\hline Custo da silagem, $\mathrm{R} \$ / \mathrm{t}$. & 21,28 & 21,28 & 21,28 & 21,28 \\
\hline Custo da silagem, R\$/t. de MS & 58,14 & 58,14 & 58,14 & 58,14 \\
\hline Custo do concentrado, $\mathrm{R} \$ / \mathrm{t}$. de $\mathrm{MS} *$ & 225,00 & 195,00 & 165,00 & 135,00 \\
\hline Consumo silagem, kg MS/dia & 6,740 & 6,414 & 6,313 & 6,121 \\
\hline Consumo concentrado, $\mathrm{kg} \mathrm{MS} / \mathrm{dia}$ & 4,493 & 4,276 & 4,208 & 4,080 \\
\hline Custo silagem, R\$/animal/dia & 0,39 & 0,37 & 0,37 & 0,36 \\
\hline Custo concentrado, R\$/animal/dia & 1,01 & 0,84 & 0,70 & 0,55 \\
\hline Custo total da alimentação, R\$/animal/dia & 1,40 & 1,21 & 1,06 & 0,91 \\
\hline Custo/kg de ganho de peso, $\mathrm{R} \$$ & 1,08 & 1,01 & 0,80 & 0,92 \\
\hline
\end{tabular}

*Considerando o preço do quilograma do grão de sorgo a $\mathrm{R} \$ 0,18$ e do grão de aveia preta a $\mathrm{R} \$ 0,11$.

no custo de alimentação, devido ao melhor desempenho dos animais alimentados com menor proporção de grão de aveia preta. Verificou-se que a eficiência biológica melhorou nos níveis com maior proporção de grão de sorgo, porém a eficiência econômica melhorou somente com a redução da proporção de grão de sorgo na dieta. Comportamento semelhante foi observado, quando se avaliaram os custos na segunda fase do confinamento com a utilização de silagem de milho, cujos dados médios são apresentados na tabela 3. Observa-se, no entanto, que os custos para produzir um quilo de ganho de peso foram maiores com a silagem de milho do que com a de sorgo, para todos os tratamentos. Este aumento no custo está relacionado diretamente com o aumento no consumo de matéria seca dos animais em função do aumento do peso vivo e também pelo maior custo de produção da silagem de milho em relação à silagem de sorgo.

A utilização de um volumoso mais caro, porém com maior densidade energética, durante a segunda fase do confinamento, visou manter o mesmo ritmo de ganho de peso dos animais durante todo o período, devido à relativa importância do planejamento da data de abate em função da variação no preço do boi gordo durante o ano. A alteração da dieta visou suprir o aumento no requerimento energético do animal à medida que este vai alcançando o grau de acabamento desejado. Este aumento ocorre em função das mudanças na composição do ganho de

Tabela 2 - Resultados do sistema produtivo durante a primeira fase do confinamento com silagem de sorgo

\begin{tabular}{|c|c|c|c|c|}
\hline \multirow{2}{*}{ Itens } & \multicolumn{4}{|c|}{ Nível de substituição } \\
\hline & $0 \%$ aveia & $33 \%$ aveia & $66 \%$ aveia & $100 \%$ aveia \\
\hline Consumo de MS, kg/animal/dia & 9,017 & 9,140 & 9,172 & 8,807 \\
\hline Ganho de peso, kg/animal/dia & 1,290 & 1,307 & 1,102 & 1,112 \\
\hline Custo da silagem, $\mathrm{R} \$ / \mathrm{t}$ de MV & 13,53 & 13,53 & 13,53 & 13,53 \\
\hline Custo da silagem, R\$/t de MS & 45,90 & 45,90 & 45,90 & 45,90 \\
\hline Custo do concentrado, $\mathrm{R} \$ / \mathrm{t}$ de $\mathrm{MS} *$ & 226,00 & 197,00 & 167,00 & 137,00 \\
\hline Consumo silagem, kg MS/dia & 5,410 & 5,484 & 5,503 & 5,284 \\
\hline Consumo concentrado, $\mathrm{kg} \mathrm{MS} / \mathrm{dia}$ & 3,607 & 3,656 & 3,669 & 3,523 \\
\hline Custo silagem, R\$/animal/dia & 0,25 & 0,25 & 0,25 & 0,24 \\
\hline Custo concentrado, $\mathrm{R} \$ /$ animal/dia & 0,81 & 0,72 & 0,61 & 0,48 \\
\hline Custo total da alimentação, R\$/animal/dia & 1,06 & 0,97 & 0,87 & 0,73 \\
\hline Custo/kg de ganho de peso, $\mathrm{R} \$$ & 0,82 & 0,74 & 0,78 & 0,65 \\
\hline
\end{tabular}

*Considerando o preço do quilograma do grão de sorgo a $\mathrm{R} \$ 0,18$ e do grão de aveia preta a $\mathrm{R} \$ 0,11$.

Ciência Rural, v. 33, n. 5, set-out, 2003. 
peso. SAMPAIO et al. (1998) verificaram que a não adequação das dietas de novilhos à nova condição da fase de crescimento para a terminação, através do aumento da densidade energética da dieta, resultou em diminuição do ganho de peso e piora na conversão alimentar. $\mathrm{O}$ aumento do requerimento energético poderia ser suprido através do aumento do nível de concentrado. No entanto, a utilização de uma silagem de melhor qualidade permite que não se altere a fração que mais onera o custo do confinamento (BRONDANI et al. 2000).

Ainda analisando a tabela 3 , observa-se que o custo com alimentação decresceu com o incremento da proporção de grão de aveia na dieta. No entanto, o custo para produzir um quilograma de ganho de peso foi menor no nível de $66 \%$ de aveia, resultado do melhor desempenho dos animais em relação ao nível de $100 \%$ de aveia. Isto demonstra a importância do desempenho animal sobre a rentabilidade do sistema, visto que a dieta com menor custo de alimentação não foi a que proporcionou o menor custo por quilo de ganho de peso. No mesmo sentido, OLIVEIRA et al. (2001) verificaram que dietas mais baratas podem ser menos rentáveis, devido ao pior desempenho animal e pior conversão alimentar, elevando o custo por unidade de produto.

$\mathrm{Na}$ tabela 4, são apresentados os dados médios do custo e da receita total do confinamento. $\mathrm{O}$ custo total com alimentação durante os 67 dias de confinamento decresceu com o aumento da proporção de aveia no concentrado. Entretanto, a receita bruta total também decresceu em função do menor desempenho dos animais. Quando se considera a diferença entre receita bruta e custo, observa-se que o maior valor foi atingido com a utilização de $33 \%$ de sorgo e $66 \%$ de aveia no concentrado. Este valor ficou acima do tratamento que apresentou o melhor desempenho animal ( $0 \%$ de aveia) e do que apresentou o menor custo de alimentação (100\% de aveia).

$\mathrm{Na}$ escolha dos componentes do concentrado, devem ser considerados os objetivos e necessidades de cada propriedade; conforme a situação pode ser mais interessante ter uma alimentação mais cara, porém que proporcione menor tempo de confinamento, devido ao melhor desempenho animal. No entanto, se o tempo e o volumoso não forem limitantes, uma alimentação mais barata pode ser mais interessante para o sistema. Além disso, a variação no preço dos produtos agrícolas durante os anos é altamente importante na tomada de decisão. Uma redução no preço do sorgo para $\mathrm{R} \$ 0,147 \mathrm{~kg}^{-1}$ é suficiente para proporcionar a mesma receita líquida nos tratamentos 0 e $100 \%$ de aveia no concentrado. $\mathrm{O}$ ponto de equilíbrio do lucro entre as dietas com 0 ou $100 \%$ de aveia no concentrado ocorre quando o preço do grão de aveia equivaler a $81 \%$ do preço do grão de sorgo.

\section{CONCLUSÕES}

A substituição do grão de sorgo por grão de aveia, depende da composição relativa dos preços de mercado dos dois grãos, pois analisando apenas a relação receita bruta/custo, conclui-se que o grão de aveia preta pode substituir o grão de sorgo totalmente, quando o preço do quilograma for menor que $81 \%$ do preço do grão de sorgo.

Tabela 3 - Apreciação econômica do sistema produtivo durante a segunda fase do confinamento com silagem de milho

\begin{tabular}{|c|c|c|c|c|}
\hline \multirow{2}{*}{ Itens } & \multicolumn{4}{|c|}{ Nível de substituição } \\
\hline & $0 \%$ aveia & $33 \%$ aveia & $66 \%$ aveia & $100 \%$ aveia \\
\hline Consumo de MS, kg/animal/dia & 11,233 & 10,690 & 10,521 & 10,201 \\
\hline Ganho de peso, kg/animal/dia & 1,294 & 1,195 & 1,331 & 0,990 \\
\hline Custo da silagem, $\mathrm{R} \$ / \mathrm{t}$. & 21,28 & 21,28 & 21,28 & 21,28 \\
\hline Custo da silagem, R\$/t. de MS & 58,14 & 58,14 & 58,14 & 58,14 \\
\hline Custo do concentrado, $\mathrm{R} \$ / \mathrm{t}$. de $\mathrm{MS} *$ & 225,00 & 195,00 & 165,00 & 135,00 \\
\hline Consumo silagem, $\mathrm{kg} \mathrm{MS} / \mathrm{dia}$ & 6,740 & 6,414 & 6,313 & 6,121 \\
\hline Consumo concentrado, $\mathrm{kg} \mathrm{MS/dia}$ & 4,493 & 4,276 & 4,208 & 4,080 \\
\hline Custo silagem, R\$/animal/dia & 0,39 & 0,37 & 0,37 & 0,36 \\
\hline Custo concentrado, R\$/animal/dia & 1,01 & 0,84 & 0,70 & 0,55 \\
\hline Custo total da alimentação, R\$/animal/dia & 1,40 & 1,21 & 1,06 & 0,91 \\
\hline Custo/kg de ganho de peso, $\mathrm{R} \$$ & 1,08 & 1,01 & 0,80 & 0,92 \\
\hline
\end{tabular}

*Considerando o preço do quilograma do grão de sorgo a $\mathrm{R} \$ 0,18$ e do grão de aveia preta a R\$ 0,11 . 


\section{REFERÊNCIAS BIBLIOGRÁFICAS}

ANUALPEC. Anuário da pecuária brasileira. São Paulo: Oesp Gráfica, 2000. 359p.

BRONDANI, I.L.; ALVES FILHO, D.C.; BERNARDES, R.A.C. Silagem de alta qualidade para bovinos. In: RESTLE, J. (Ed.). Eficiência na produção de bovinos de corte, Santa Maria: UFSM, 2000. p.185-204.

BÜRGI, R. Confinamento estratégico. In: SIMPÓSIO DE BOVINOCULTURA DE CORTE, REUNIÃO ANUAL DA SOCIEDADE BRASILEIRA DE ZOOTECNIA, 38., 2001, Piracicaba. Anais... Piracicaba : SBZ/Gmosis, [2001]. Semi-15.

NATIONAL RESEARCH COUNCIL - NRC. Nutrient requirement of beef cattle. 6.ed. Washington, DC, 1984. 50p.

NATIONAL RESEARCH COUNCIL - NRC. Nutrient requirement of beef cattle. 7.ed. Washington, DC, 1996. 232p.

NEUMANN, M. Caracterização agronômica quantitativa e qualitativa da planta, qualidade de silagem e análise econômica em sistema de terminação de novilhos confinados com silagem de diferentes híbridos de sorgo (Sorghum bicolor, L. Moench). 2001. 156f. Dissertação (Mestrado em Zootecnia) - Curso de Pós-graduação em Zootecnia, Universidade Federal de Santa Maria.
OLIVEIRA, B.S.Y. et al. Desempenho de bovinos terminados em confinamento com diferentes volumosos. In: REUNIÃO ANUAL DA SOCIEDADE BRASILEIRA DE ZOOTECNIA, 38., 2001, Piracicaba. Anais... Piracicaba : SBZ/Gmosis, [2001]. Nutrição de ruminantes. 6-0844.

PASCOAL, L.L.; VAZ, R.Z.; ROSO, C. Confinamento versus pastagem na terminação de bovinos. In: RESTLE, J. (Ed.). Confinamento, pastagens e suplementação para produção de bovinos de corte. Santa Maria : UFSM, 1999. p.178-190.

RESTLE, J.; ALVES FILHO, D.C.; NEUMANN, M. Eficiência na terminação de bovinos de corte. In: RESTLE, J. (Ed.). Eficiência na produção de bovinos de corte. Santa Maria: UFSM, 2000. p.277-303.

RESTLE, J.; VAZ, F.N. Confinamento de bovinos definidos e cruzados. In: LOBATO, J.F.P.; BARCELLOS, J.O.J.; KESSLER, A.M. Produção de bovinos de corte. Porto Alegre : EDIPUCRS, 1999. p.141-168.

SAMPAIO, A.A.M. et al. Efeito da suplementação protéica sobre crescimento, terminação e viabilidade econômica de bezerros mestiços Canchim confinados pós-desmama. Revista Brasileira de Zootecnia, Viçosa, v.27, n.4, p.823-831, 1998.

VAZ, F.N.; VAZ, R.Z.; ROSO, C. Tipos e níveis de concentrado para confinamento. In: RESTLE, J. (Ed.). Eficiência na produção de bovinos de corte. Santa Maria : UFSM, 2000. p.219-257. 